\title{
Words' Origin of an Affective State, but not Valence, Shape the Reaction Latencies in a Word-Sign Choosing Ambiguous Task
}

\author{
Kamil K. Imbir ${ }^{1}$ \\ Published online: 28 August 2017 \\ (C) The Author(s) 2017. This article is an open access publication
}

\begin{abstract}
This paper presents data concerning the impact of word connotations differing in valence and origin on ambiguous decisions. The origin factor describes engagement of automatic vs. controlled processing mechanisms in formation of an emotional reaction to the stimuli (words, in this case). Other potentially important factors such as arousal, concreteness, frequency of appearance in language and length were matched across conditions. The task was introduced as intuition related and participants were supposed to guess which one of two hexagrams, introduced as pictorial symbols from an East Asian language, best suited the meaning of certain words. The expectation was that the origin of a word's affective connotations would influence decision making speed, and reaction latencies would be longer for reflectively originated words compared to automatically originated ones. The rationale for such a hypothesis is that reflective origins of emotional reactions are part of rational, multi-criteria processing, representing more complex mechanisms than automatic origins of emotional reactions based on experiential, automatic appraisals, representing less complex processing. For reflectively originated words, reaction latencies for word-sign matching tasks were longer than for automatically originated ones. No valence effects were found. Also no effects of the manipulations were found for time spent look at the words or location (top or bottom) of the chosen response in an ambiguous word-symbol matching task. This suggests that, indeed,
\end{abstract}

Electronic supplementary material The online version of this article (https://doi.org/10.1007/s12144-017-9669-6) contains supplementary material, which is available to authorized users.

Kamil K. Imbir

kamil.imbir@gmail.com

1 Faculty of Psychology, University of Warsaw, 5/7 Stawki St., 00-183 Warsaw, Poland origin influences only the type of processing that subsequently occurs, namely whether choices reflected systematic or heuristic processing.

Keywords Ambiguity processing · Incidental affect · Origins of an affective reactions to stimuli . Choices under uncertainty

\section{Introduction}

Human mental processing is susceptible to many incidental factors, especially the affective state of the individual (Clore and Huntsinger 2007; Payne et al. 2005). The easiest way to see the effects of emotions on cognition is to inspect situations when one's knowledge is uncertain, and thus ambiguity is involved in giving the answers (Ellsberg 1961; Heath and Tversky 1991; Payne et al. 2005). In addition, a useful perspective for investigating emotion-cognition relations has been the notion that the human mind has dual processing systems, one that is automatic and one that is more controlled (Imbir 2016a). This approach (Gawronski and Creighton 2013) has attracted more and more attention from the scientific community. Dual process theories compare and contrast uncontrolled and automatic processing mechanisms responsible for heuristic thinking with controlled and rational processing mechanisms responsible for systematic thinking (Kahneman 2011).

Epstein (2003) has described these two distinct systems as the experiential and the rational mind. The research reported in this paper investigates the role of these two systems in the diversity of emotional reactions observed in everyday situations (Kagan 2007). We (Imbir 2015, 2016a; Jarymowicz and Imbir 2015) recently proposed that some emotional states are based on automatic appraisals, while others result from systematic and reflective emotional processes. In order to measure the origin of an affective reaction to stimuli, a Self- 
Assessment Manikin (SAM) scale was developed. This scale allowed us to measure the subjectively perceived emotions with automatic origins described as derived from the heart, or emotions with reflective origins described as derived from the mind. Both aspects of emotional reactions to stimuli were based on the well known metaphor of heart vs. mind, representing to some extent the meaning of the dual mind distinction (Imbir 2015, 2016a; Jarymowicz and Imbir 2015). The SAM scale developed to measure the origin of an affective reaction to stimuli is presented in Fig. 1. The aim of the current study was to examine if the originrelated emotional complexity of verbal stimuli would influence the way ambiguous decisions concerning word meanings are processed. The answer to this question is important not only for the purpose of understanding emotions, but also to achieve a better understanding of dual-mind functioning (Imbir 2016a).

\section{Dual Mechanisms of Processing in Emotion-Cognition Relationships}

The main assumption underlying the dual-mind theories is that there exist two different modes of processing, namely automatic and controlled (Moors and De Houwer 2006). The dual-mind framework received some criticism concerning the large number of postulated dualities sometimes contradicting one another (see: Keren and Schul 2009) and the multi-criteria based description of processing in each way, thus the congruency of those criteria is hard to achieve in everyday situations (Moors and De Houwer 2006). Despite this, when focusing only on the mechanisms underlying both types of processing (Strack and Deutsch 2004), and thus on similarities rather than differences between the different processes (e.g. Imbir 2016a; Jarymowicz and Imbir 2015), one may find that behavioral responses to stimulation may be mediated by automated, associative processes or based on verbalization and rules of logic reasoning (Strack and Deutsch 2004). Those two mechanisms can lead to different consequences in everyday situations, resulting in fast vs. slow responses (Kahneman 2011) differing in some instances in the accuracy of the answer.

Some dual mind theories state that emotions only result from automatic processing (Epstein 2003; Kahneman 2011). However, there is no reason to assume that rational or reflective processing does not also contribute to emotional reactions (Jarymowicz and Imbir 2015). For that reason, the distinction between so called automatic and reflective emotional processes was proposed as an emotional manifestation of experiential and rational minds (Epstein 2003; Imbir 2016a). Emotions of automatic origins are those based on fixed, evolutionary derived evaluative criteria of biological value (Damasio 2010). They do not need language to appear, but are represented in language by labeling the automatically originated states. Put simply, one can feel the pain, even without naming its source. According to Kahneman (2011), emotional reactions to the emotional expressions of others are a type of automatically originated experience. The reaction appears effortlessly, immediately and with total certainty of own feelings (Zajonc 1980). Everything beneficial for health or happiness (e.g. smiling faces of others, tasty food or sunny weather) is evaluated positively, while all threats are evaluated negatively (e.g. a man with angry face approaching us, smelly food or even a rainy day). The evaluations are fast and when they are not pronounced enough to evoke an emotional episode, they affect the general, currently experienced mood (Russell 2003).

One can argue that automatically originated emotional experiences do not exceed all possibilities for emotions to appear in the human mind. Some emotional processes are based on deliberation and are often called self-conscious emotions (Lewis 1995; Weiner 2005) or appraisal based emotions (Scherer 2004). Simply naming states and situations allows us to compare them to some kind of a standards (e.g. selfstandards: Lewis 1995) of what is bad or good. Due to this process one can reappraise the situation and develop secondary emotions in addition to the initial, primary affective reaction. The mechanism of reflective emotion formation is cognitive resource demanding, due to the involvement of the propositional mechanisms postulated by Strack and Deutsch (2004). Jarymowicz and Imbir (2015) argue that reflective

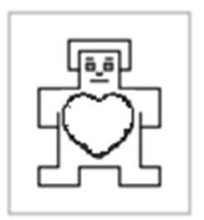

1

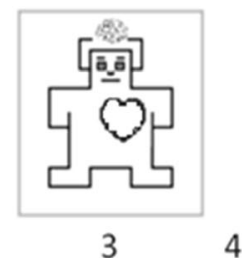

4

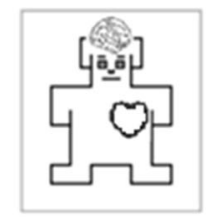

5

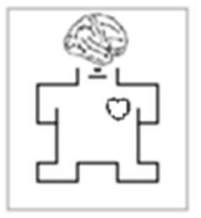

7

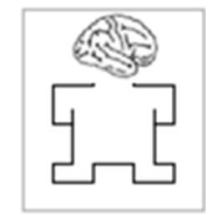

9

Fig. 1 The SAM scale developed for origin of an affective reaction to stimuli measure. The scale was accompanied by the description stating: "The first picture shows an individual who is overwhelmed with appeals from the heart - words that could represent these experiences include being beside oneself, complete commitment, full engagement,

impulsivity, spontaneity, lack of hesitation. The last picture shows a person who is under the sway of the mind, who is reflective - words that could be used to represent this state include feelings that result from contemplation, planning, consideration, prediction, choices, or comparisons." (Imbir 2015, 2016b) 
emotion may appear when mental representations of the current situation of an individual are compared to the situation they desire or think ought to exist. Such an evaluative standard (Reykowski 1989) is the sentence based representation of an evaluated situation, which may be compared to the current state, resulting in an emotional reaction. The process of making comparisons consumes energy; thus, one may avoid the effort of doing so just as one may spare themselves the effort of systematic thinking and use heuristics instead (Kahneman 2011). The deliberative base of reflective emotional state elicitation leads to a great diversity of possible emotional states and may lead to very different responses to the same situation. Simply put, different people may use different evaluative standards to assess a given situation, and thus feel different emotional states. The difference between automatic vs. reflective emotional states has only to do with the mechanism of emotion formation, while emotional outcomes, in terms of physiological, hormonal or autonomic nervous system reactions, should be similar (see: Imbir 2016a; Kagan 2007).

On the basis of the dual-mind framework, the model of emotion-cognition relations was formulated recently (Imbir 2016a), stating that both the emotional and cognitive domains should be understood as composed of two types of processes, namely automated and controlled. Such a model postulates that emotion-cognition interactions are in fact four different types of processes. They include, on one hand, processes involving the same system: (1) automatic emotions influencing heuristic cognition and (2) reflective emotions influencing systematic cognition. The former involves the experiential system and the latter the rational system (Epstein 2003). Additionally, cross-systems interactions exist: (3) when automatic emotions influence systematic cognition or (4) reflective emotions alter heuristic based cognitive processes (see: Imbir 2016a). However, our contention is that although these cross-system influences can occur, the predominant impact of emotional processes deriving from one or the other system (automatic/heuristic or reflective/systematic) will be to promote cognitive processing within the same system. The theoretical model predicting those relationships derived from Imbir (2016a) is presented in Fig. 2.

\section{Origin of Emotion Operationalizational and Theoretical Issues}

The remaining theoretical issue is how to manipulate the affective state of individuals, using clearly identifiable automatic vs. reflective processes. It is a tricky issue, because as previously stated, the nature of processes underlying the experiential and rational mind are very different (Epstein 2003) and thus automatic and reflective emotions are based on distinct mechanisms of formation (automatic appraisals of biological value and deliberative appraisals based on evaluative standards: see: Jarymowicz and Imbir 2015). The solution to this problem was found with use of language stimuli as universal representations of very different states of an organism (Rolls 2000) that include very vivid affective connotations (Osgood et al. 1957). For that reason the origin connotations were searched for verbal stimuli and assessed by people while reading them (Imbir 2015). Origin assessments, based on the SAM scale (cf. Fig. 1), appeared to be a reliable and stable measure of which mode underlies emotional reactions (Imbir 2015).

It is worth highlighting that the experiential and rational minds work with different kind of stimuli (Epstein 2003). The experiential mind uses a language of objects and experiences with them. The rational mind is based on concepts and rules governing relations between them. The ReflectiveImpulsive Model (RIM: Strack and Deutsch 2004) states that the impulsive system produces behavior based on associations between objects (input-behavioural output loops) while the reflective system produces behavior as a result of a decision process involving weighing the likelihood and positivity of the possible outcomes of different choices (based on concepts that are processed in the context of sentences with the use of propositional mechanisms). At first glance, each system seems to focus on different types of stimuli. The difference between them we may term concreteness (c.f. Ferré et al. 2012; Kanske and Kotz 2007). Concrete stimuli are those having a certain representation in the material world. Abstract stimuli may represent ideas or concepts that are not represented in the material world, but observed by the
Fig. 2 Theoretical model of relation between origin of an emotional state of words and the type of processing in an ambiguous word-sign matching paradigm. On the basis of Imbir's (2016a) model of emotion and cognition interactions

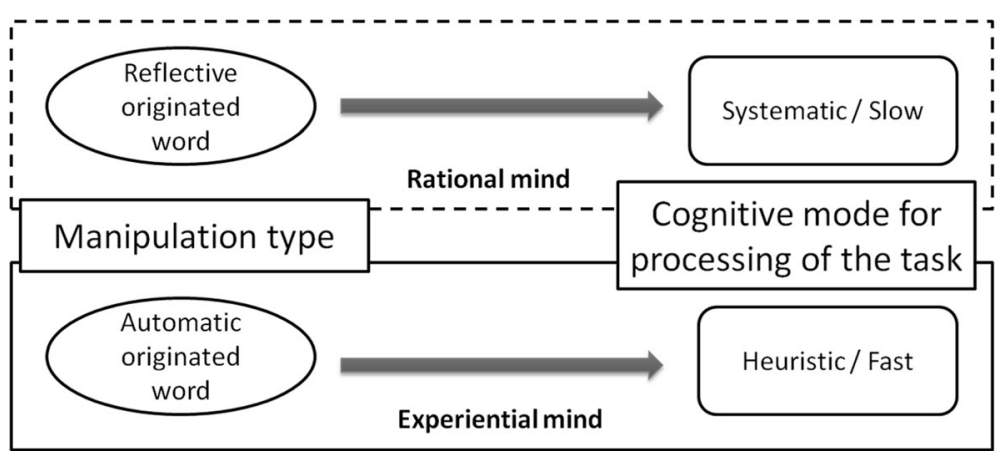


outcomes they cause in the material world (revolutionary ideas make a mess in the material word, despite the fact that revolution is only an idea represented in peoples' minds). Concreteness of verbal stimuli was found to be an important factor that modulates Event Related Potential (ERP) correlates of emotional word processing (c.f. Barber et al. 2013; Kanske and Kotz 2007; Palazova et al. 2013). In other words, concrete stimuli are processed quite different than abstract ones in terms of brain responses to them. What is more, concreteness was found to interact with valence; abstract words were found to be perceived in a more valenced way than concrete words (c.f. Vigliocco et al. 2014).

Concreteness therefore seems to be a factor very likely to interact with complexity of affective reactions. Results of a normative study of Polish words (Imbir 2016b) suggests that the possible overlap between the "concreteness" and "origin" dimensions measured by Pearson's $r$ correlation of assessments made in ANPW_R is weak $(r=.301, p<.001)$, and therefore it is reasonable to treat them as different aspects of stimulus complexity. While origin reflects the underlying mechanism of emotion formation, concreteness represents the nature of the object described as concrete or abstract. With the use of the SAM origin scale, a list of stimuli differing in origins (see: Method section) was selected and this allowed testing of the model presented in Fig. 2.

\section{Ambiguity Processing and Dual Aspects of Emotional State}

The remaining question is in which situations system specific cognition may be triggered by an emotional state. It has to be a very specific task, with no obvious way of achieving the answer. Ambiguous stimuli processing best fits such expectations. Ambiguity is a type of uncertainty of meaning. In the processing of ambiguity, several interpretations are plausible. With ambiguous stimuli, for example, one visual figure or image can be interpreted in two different ways, depending on presuppositions (e.g. multistable perception in The Necker cube; Eagleman 2001) or prior knowledge (Franz et al. 2000). Not only can visual illusions be treated as instances of ambiguity, but also information uncertainty can lead to ambiguity elicitation. Humans tend to reduce the level of uncertainty each time they are supposed to face the new problem (Ellsberg 1961; Heath and Tversky 1991).

Conceptual ambiguity was used in the current study. When stimuli in the task have no particular meaning, performance should be dependent on properties of the sounding objects or priming clues. The ambiguous task designed for this study was based on the procedure introduced by Murphy and Zajonc (1993). The idea in one of their studies was to describe pictographs originating in the Chinese language as representations of objects, which were assessed as bad or good. In fact, there were no premises for assessing the objects, and thus the participants' assessments were found to be susceptible to the affective manipulation caused by the facial expressions of emotion presentation, lasting only briefly. Chinese pictographs were also used in the Affect Misattribution Procedure (Payne et al. 2005), a task in which affect delivered by presentation of affectively charged stimuli prime the interpretation of unrelated, neutral stimuli. The same idea was used in the creation of the implicit self-reference measure (Błaszczak and Imbir 2012) with use of hexagram stimuli (see: Fig. 3) described as a Far Eastern cultural symbol representing traits of character or personality. The task was to answer if the trait is related to participants' self or is unrelated. In both cases, such defined interpretation of ambiguous stimuli meaning was found to be a good measure of emotional outcomes for cognitive processes.

\section{Aim and Hypothesis}

The aim of the current study was to investigate the role of word connotations in the performance of an ambiguous task involving choosing a graphical representation that best represents the meaning of a word (Antosz and Imbir 2017). Based on the model presented in Fig. 2, one may expect the emotionally charged stimuli to promote processing characteristic of different mental systems depending on the origin of the stimuli. The outcomes of such different mechanisms of processing should be especially visible under conditions of uncertainty, namely when the task is ambiguous. Automatic originated stimuli should prime heuristic and thus fast (Kahneman 2011) processing, while reflective originated stimuli should prime systematic and thus slow (Kahneman 2011) task processing. Alternatively, the complexity (emotional, but not cognitively based) of stimuli may prime more automated, simplified, thus faster processing for automatic originated stimuli and controlled, multi-aspectual, thus slower processing for reflective originated stimuli. The expected differences concerned mainly reaction latencies as indicators of processing ease.

\section{Method}

\section{Participants}

Sixty students ( 30 women and 30 men) from different colleges and universities (counterbalanced with respect to their academic field of study - social sciences, humanities, natural sciences, engineering or medical sciences) were invited into a study of intuition. They were from 19 to 27 years old $(M=21.52, S D=2)$, had normal or corrected to normal vision and were Polish language native speakers. None of the participants had experience with Far East cultures or had learned any Far East languages. Participation was voluntary, but rewarded with a small gift card. The number of participants 
Fig. 3 Single trial of wordhexagram matching task

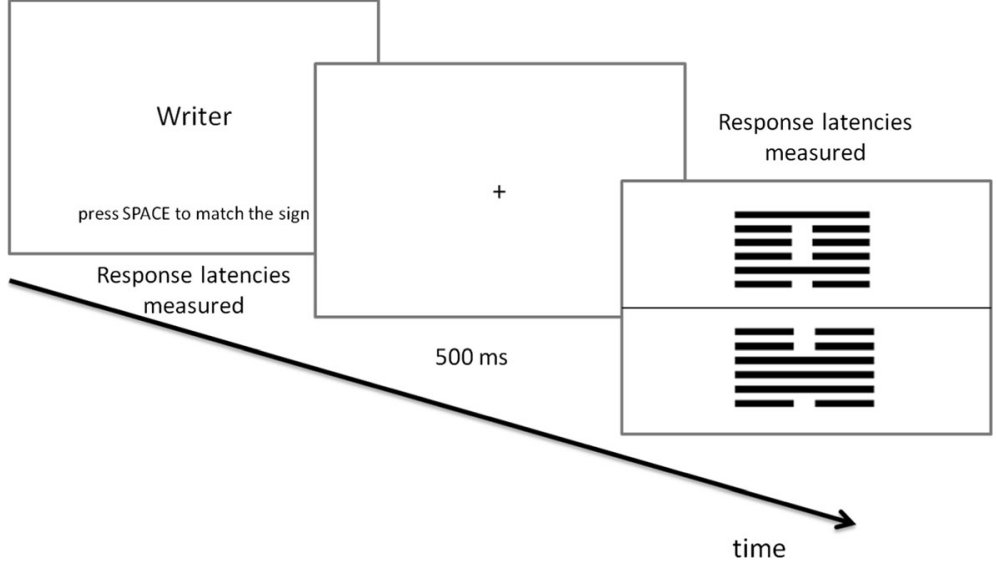

appearance in language had a highly skewed distribution, and therefore their $\log$ transformations were analyzed. Table 2 presents the result of the analyses. It appears that indeed stimuli were selected in a way that allowed manipulation of valence and origin levels with control of other possible important factors. The origin groups of words appeared to differ slightly in length, however. Simple contrast analysis showed that the difference concerned words of an automatic origin versus words of no particular origin: $t(132)=2.62, p=0.01$, while the remaining contrasts were not significant. Automatically originated words were $M=7.3(S E M=0.3)$ letters long, while words of no particular origin were $M=6.2(S E M=0.3)$ letters long.

\section{Ambiguous Task}

In the current study, participants performed a task involving making judgments about ambiguous hexagram stimuli (see: Fig. 3; see also: Błaszczak and Imbir 2012). Participants were told that hexagrams are the Far East pictorial alphabet signs describing objects and states. The task was to choose, by clicking the up or down arrow on a computer keyboard, which of two hexagrams better represented the meaning of the previously presented word. Such a paradigm was introduced recently by Antosz and Imbir (2017) and revealed that the decisions made were influenced by the type of word used.

Each hexagram consisted of six horizontal black lines separated by five white lines. On some black lines four white spaces either on central or distant locations were randomly placed. A total of 64 distinct hexagrams were used in the study, appearing on the screen in various sequences. The hexagrams were paired randomly and all appeared more than once, but never in the same location or within the same pair.

\section{Apparatus}

The whole experiment was prepared using the E-Prime 2.0 environment. This software allows for creation of experimental
3 (valence levels) $\times 3$ (origin levels) ANOVA analyses were conducted for each dimension measured. Frequencies of 
Table 1 Descriptive statistics $(M, S D)$ for groups of words used in factorial manipulation

\begin{tabular}{|c|c|c|c|c|c|c|c|c|c|}
\hline & $M$ & $(S D)$ & $M$ & $(S D)$ & $M$ & $(S D)$ & Origin Category & $M$ & $(S D)$ \\
\hline Valence & 3.50 & $(0.36)$ & 5.02 & $(0.56)$ & 6.71 & $(0.35)$ & Automatic & 5.07 & (1.39) \\
\hline Origin & 4.45 & $(0.53)$ & 4.58 & $(0.37)$ & 4.33 & $(0.70)$ & & 4.45 & $(0.55)$ \\
\hline Arousal & 4.37 & $(0.49)$ & 4.15 & $(0.55)$ & 4.28 & $(0.80)$ & & 4.27 & $(0.62)$ \\
\hline Concreteness & 4.31 & $(1.15)$ & 3.95 & $(0.74)$ & 4.48 & $(1.20)$ & & 4.24 & (1.05) \\
\hline NoL & 7.20 & $(2.65)$ & 7.47 & (1.96) & 7.40 & $(2.41)$ & & 7.36 & $(2.31)$ \\
\hline Ln_freq & 5.21 & (1.91) & 5.65 & (2.03) & 5.73 & $(2.28)$ & & 5.53 & (2.04) \\
\hline Valence & 3.37 & $(0.36)$ & 5.19 & $(0.54)$ & 6.38 & $(0.32)$ & Control (0) & 4.98 & $(1.32)$ \\
\hline Origin & 5.41 & $(0.31)$ & 5.49 & $(0.30)$ & 5.36 & $(0.35)$ & & 5.42 & $(0.32)$ \\
\hline Arousal & 4.15 & $(0.23)$ & 4.12 & $(0.67)$ & 4.04 & $(0.51)$ & & 4.11 & $(0.49)$ \\
\hline Concreteness & 4.05 & (1.12) & 3.96 & (1.32) & 4.17 & $(0.74)$ & & 4.06 & (1.06) \\
\hline NoL & 6.47 & (2.03) & 5.27 & (1.33) & 6.93 & $(2.02)$ & & 6.22 & (1.92) \\
\hline Ln_freq & 5.48 & $(2.28)$ & 5.97 & $(1.27)$ & 6.61 & $(2.02)$ & & 6.02 & (1.92) \\
\hline Valence & 3.66 & $(0.35)$ & 5.30 & $(0.39)$ & 6.49 & $(0.40)$ & Reflective & 5.15 & (1.23) \\
\hline Origin & 6.46 & $(0.30)$ & 6.63 & $(0.41)$ & 6.63 & $(0.56)$ & & 6.57 & $(0.43)$ \\
\hline Arousal & 4.32 & $(0.49)$ & 3.93 & $(0.47)$ & 4.03 & $(0.36)$ & & 4.10 & $(0.46)$ \\
\hline Concreteness & 4.17 & (1.13) & 4.09 & (1.17) & 4.41 & (1.07) & & 4.22 & (1.11) \\
\hline $\mathrm{NoL}$ & 7.07 & (1.75) & 6.27 & $(1.62)$ & 7.20 & $(2.27)$ & & 6.84 & (1.91) \\
\hline Ln_freq & 5.42 & $(1.37)$ & 6.53 & (1.79) & 6.01 & $(1.22)$ & & 5.99 & $(1.52)$ \\
\hline Valence category & \multicolumn{2}{|c|}{ Negative } & Neutral & & \multicolumn{2}{|c|}{ Positive } & & Total & \\
\hline Valence & 3.51 & $(0.37)$ & 5.17 & $(0.50)$ & 6.53 & $(0.38)$ & Total & 5.07 & $(1.31)$ \\
\hline Origin & 5.44 & $(0.92)$ & 5.57 & $(0.92)$ & 5.44 & (1.09) & & 5.48 & $(0.97)$ \\
\hline Arousal & 4.28 & $(0.42)$ & 4.07 & $(0.56)$ & 4.12 & $(0.58)$ & & 4.16 & $(0.53)$ \\
\hline Concreteness & 4.18 & (1.11) & 4.00 & $(1.08)$ & 4.35 & $(1.01)$ & & 4.18 & $(1.07)$ \\
\hline NoL & 6.91 & (2.15) & 6.33 & (1.86) & 7.18 & $(2.20)$ & & 6.81 & $(2.09)$ \\
\hline Ln_freq & 5.37 & $(1.85)$ & 6.05 & $(1.72)$ & 6.12 & (1.89) & & 5.85 & (1.84) \\
\hline
\end{tabular}

Source: Imbir et al. (2016) protocols assuring random presentation of stimuli as well as registration of the response types and response latencies. The procedure was run on a standard laptop computer with a 15-in. monitor.

\section{Design}

A three (negative, neutral, or positive valence) by three (of automatic, reflective, or intermediate/unknown origin) within-
Table 2 Properties of the experimental words

\begin{tabular}{lccc}
\hline Dimension & $\begin{array}{l}\text { Main effect of valence } \\
\text { words groups }\end{array}$ & $\begin{array}{l}\text { Main effect of origin } \\
\text { words groups }\end{array}$ & $\begin{array}{l}\text { Interaction of valence and } \\
\text { origin words groups }\end{array}$ \\
\hline Valence & $\boldsymbol{F}(\mathbf{2 1 2 6})=\mathbf{6 0 7 . 4 4}$, & $F(2126)=1.88$, & $F(4126)=2.09, p=0.086$, \\
& $\boldsymbol{p}<\mathbf{0 . 0 0 1}, \boldsymbol{\eta}^{2}=\mathbf{0 . 9 1}$ & $p=0.16, \eta^{2}=0.03$ & $\eta^{2}=0.062$ \\
Origin & $F(2126)=1.27$, & $\boldsymbol{F}(\mathbf{2 1 2 6})=\mathbf{2 5 4 . 5 5}$, & $F(4126)=0.5, p=0.74$, \\
& $p=0.28, \eta^{2}=0.02$ & $\boldsymbol{p}<\mathbf{0 . 0 0 1}, \eta^{2}=\mathbf{0 . 8 0}$ & $\eta^{2}=0.016$ \\
Arousal & $F(2126)=1.98$, & $F(2126)=1.44$, & $F(4126)=0.5, p=0.72$, \\
& $p=0.14, \eta^{2}=0.02$ & $p=0.24, \eta^{2}=0.02$ & $\eta^{2}=0.016$ \\
Concreteness & $F(2126)=1.19$, & $\mathrm{F}(2126)=0.4, p=0.67$, & $F(4126)=0.12, p=0.98$, \\
& $p=0.31, \eta^{2}=0.02$ & $\eta^{2}=0.006$ & $\eta^{2}=0.004$ \\
number of letters & $F(2126)=2.01$, & $\boldsymbol{F}(\mathbf{2 1 2 6})=\mathbf{3 . 4 8 ,}$, & $F(4126)=0.82, p=0.52$, \\
& $p=0.14, \eta^{2}=0.03$ & $\boldsymbol{p}=\mathbf{0 . 0 3 4}, \eta^{2}=\mathbf{0 . 0 5 2}$ & $\eta^{2}=0.025$ \\
Frequency (LN & $F(2126)=2.3, p=0.11$, & $F(2126)=1.0, p=0.37$, & $F(4126)=.44, p=0.78$, \\
transformation & $\eta^{2}=0.04$ & $\eta^{2}=0.016$ & $\eta^{2}=0.014$ \\
\hline
\end{tabular}

Expected main effects of valence for valence ratings and of origin for origin ratings are presented in bold. Lack of effects for all of the other controlled dimensions suggests validity of the material used 
subjects design was employed. A total of 135 words were presented, consisting of 15 from each of the nine possible combinations of valence and origin. Words were presented in a random order. Each word appeared only once during the procedure.

\section{Procedure}

Participants were invited into a study focusing on intuition. They were told that the boundaries of human insight were being investigated. The task was introduced to them as picking one of two different symbols from an East Asian language as best suiting the meaning of the word presented to them. They were assured that hexagrams indeed are the meaningful pictorial representations of words in the language used by a small population. Two training trials of the task were provided in order to assure that participants understood the task itself. Then, the main part of the experiment, consisting of 135 trials involving choosing which of two symbols best represented the meaning of a randomly chosen word (see: Antosz and Imbir 2017), began. Each trial began with the display of one of the words. The task was to read the word and keep it in mind for a while, until the hexagrams appeared. The length of time the word was displayed was self-regulated by the participants. They were supposed to press the key described as "proceed to the symbols" when they were ready. The amount of time they kept the word displayed was measured. After a $500 \mathrm{~ms}$ delay, two hexagrams (Błaszczak and Imbir 2012) were displayed in a vertical position. Hexagrams were separated from one another by a thin black line (see: Fig. 3). Time spent on decision making and the type of decision were measured. Figure 2 presents the single trial of the experimental procedure and examples of two different hexagrams.

\section{Data Treatment and Analytic Strategy}

Data from all 60 participants were included in the analysis. The total number of trials was 8100 (= 60 participants $\times 135$ trials), but the inspection of the distribution of reaction latencies revealed some outliers. Mean reaction latencies in the hexagram matching task for all subjects were $M=2268 \mathrm{~ms}$ with $S D=2081 \mathrm{~ms}$, with a range from $9 \mathrm{~ms}$ to $33,919 \mathrm{~ms}$. Subject-wise outlier reduction was applied. For each subject, trials shorter than $300 \mathrm{~ms}$ (found to be the lowest time needed to inspect the visual field), of which there were 266 (3.28\% of the total) overall, or more than $2 S D$ longer than mean reaction time latency (239 trials equals $2.95 \%$ of the total number of trials) were deleted. After this operation the latencies ranged from $300 \mathrm{~ms}$ to $11,699 \mathrm{~ms}$ with $M=1959 \mathrm{~ms}$ and $S D=1338 \mathrm{~ms}$. Raw reaction latencies data differed from a normal distribution $($ Skewness $=2.07$, Kurtosis $=6.98$ ). The reaction latencies were therefore subjected to a natural logarithmic $(\ln )$ transformation. Such a transformation is a standard procedure for reaction time data allowing the analysis of right-skewed (see: Heathcote et al. 1991) distributions using parametric statistics. Ln transformation resulted in normalization of the reaction latencies data distribution (Skewness $=-.12$, Kurtosis $=-.06$ ). All data (responses, reaction latencies and $\log$ transformed reaction latencies) were aggregated across participants and conditions.

A 3 (valence) $\times 3$ (origin) repeated measures ANOVA was conducted for three different dependent variables. The reaction latencies analysis was performed with log transformed data (reported in the text), but the figures show raw reaction times in milliseconds. This is because raw data are easier to understand and interpret.

\section{Results}

\section{Time Spent on Ambiguous Symbol Choice}

ANOVA analysis conducted on $\ln$ transformed times spent on selecting which hexagram best represented the target word revealed no main effect of emotional valence of words, $F(2$, $58)=.4, p=.67, \eta^{2}=.01$. A statistically significant main effect of origin was found, $F(2,58)=5.41, p=.007$, $\eta^{2}=.16$. Simple contrast analysis with Bonferonni correction for multiple comparisons showed that participants made their choice more quickly when the target word was of automatic origin (log transformed $M=7.45, S E M=.073$ ) than when it was of reflective origin $(M=7.49, S E M=.075): F(1$, $59)=7.14, p=.03, \eta^{2}=.11$ or when it was not of specified origin (control conditions; $M=7.48, S E M=.072): F(1$, 59) $=7.92, p=.02, \eta^{2}=.12$. The simple contrast of control and reflective originated words was not significant. No significant interaction between valence and origin was found: $F(4$, $56)=.58, p=.68, \eta^{2}=.04$. The pattern of results is displayed in Fig. 4.

\section{Type of Answer}

ANOVA conducted for type of answer given ( 1 coded as upper hexagram choice, 0 coded as lower hexagram choice) revealed no significant effects of the words' properties. There was no significant main effect of valence of emotionally charged words: $F(2,58)=.81, p=.45, \eta^{2}=.03$ nor origin of emotional charge: $F(2,58)=2.07, p=.14, \eta^{2}=.07$. Also, the interaction of valence and origin was not significant: $F(4$, $56)=.89, p=.48, \eta^{2}=.06$. The mean response in all experimental manipulation conditions was .49 with $S E M$ of .008 .

\section{Time Spent Examining the Words}

ANOVA analysis conducted on $\ln$ transformed display times for the words revealed no significant effects. There was no 


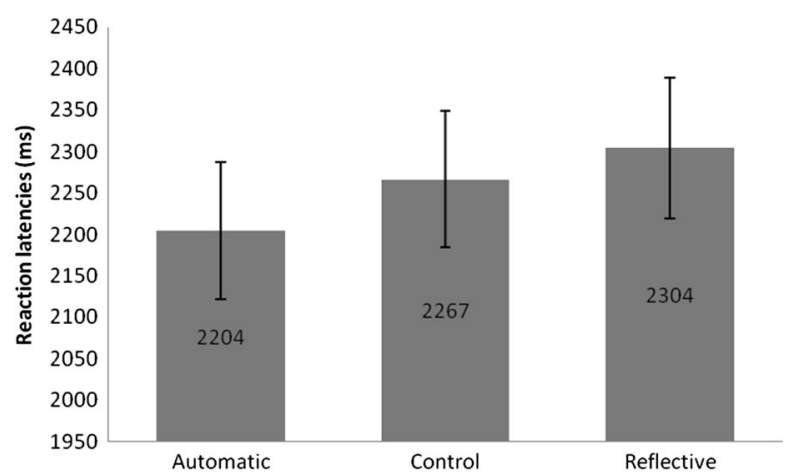

Fig. 4 Reaction latencies in hexagram choosing task. Error bars represent SEM

significant main effect of word valence: $F(2,58)=1.19$, $p=.31, \eta^{2}=.04$, nor origin of emotional meaning: $F(2$, $58)=.22, p=.8, \eta^{2}=.01$. Also, the interaction of valence and origin was not significant: $F(4,56)=.11, p=.98, \eta^{2}=.01$. The mean display time for the words in the experimental manipulation was $951 \mathrm{~ms}$ ( $\log$ transformed $M=6.67$ ) with a standard error of measurement equal to $46 \mathrm{~ms}$ (log transformed data $S E M=.045$ ).

\section{Discussion}

The pattern of results revealed that word-symbol matching decisions took more time when the word was of reflective, compared to automatic origin. Results also showed no differences in time spent examining the words, which suggests that the words chosen were well balanced and selected in terms of their complexity (e.g. concreteness or frequency of appearance in language). Also the type of decision made did not differ significantly across conditions. The lack of those two effects suggests that: (1) coding of words differing in origin took the same amount of time, not surprising since all stimuli were aligned in concreteness, the measure of cognitive complexity of stimuli (concrete vs. abstract, see: Moors et al. 2013) and (2) the task was indeed ambiguous, because it did not provoke any bias towards choosing a symbol in one or the other of the two possible locations. The above described pattern of results is consistent with the results of an earlier study using this paradigm, but including only two valence levels and two origin levels, as well as additional manipulation of a suggested to participants a wise processing speed (slow vs. fast; Antosz and Imbir 2017). In this previous experiment, origin of words caused the same pattern of differences - longer response latencies for symbol choice for reflective originated words than for automatically originated words. Antosz and Imbir (2017) found also, that suggestion of speed of answering influenced the processing of the task in a way that shortening reaction latencies was observed in "fast means wise" conditions in comparison to "slow is wise" conditions.
In light of the results, it appears to be important to understand more about the nature of the task used in this experiment. First of all, participants had to read the word and keep it in mind for half a second (see: Fig. 3). No suggestions concerning remembering were given, but time for this was unlimited. Participants indicated when they were ready for the symbol display. Then visual inspection, encoding of symbols and comparisons to the meaning of the word took place. It is crucial for purposes of understanding the results to remember that the word had to be kept in mind until the answer to the question "which one of presented hexagram stimuli better represents the meaning" was given. Since words differed in origin and affective tone, they should provoke system specific mechanisms of processing (Imbir 2016a). Automatically originated words should evoke the experiential mind and thus fast and heuristic processing. Reflectively originated stimuli should evoke rational mind mechanisms, and thus slow and systematic processing.

The susceptibility of the introduced word-symbolmatching task to the affective meaning of the stimuli (defined as origin of an affective state differences) may be interpreted as support for the validity of ambiguous properties of designed paradigms. Simply, there is no particular answer that may be suggested to participants. The results of the current study do not support the claim that vertical positioning of the stimuli is associated with valence (Meier et al. 2007), upper for positive and lower for negative valence. No valence effect was found for response type or for response latency. This result is in line with other studies using different paradigms showing that when controlling for factors such as arousal or origin of emotionally charged materials, the valence effects disappear (Burt 2002; Imbir and Jarymowicz 2013; Siegle et al. 2002; Williams et al. 1996). Without care in controlling for those factors, one may compare, for example, negatively valenced and highly arousing stimuli with positively valenced and low arousing ones, and arrive at a mistaken conclusion about the impact of valence.

It is worth noting that although in this study words were selected in order to create a factorial experimental manipulation, one may argue that in fact only behavioral correlates (i.e., judgment latency) of processing mode (heuristic vs. systematic) were measured. It is especially true because the direct manipulation of a cognitive processing mode is rather difficult to achieve (c.f. Antosz and Imbir 2017). The fact that our research used stimuli whose origin had only indirectly been determined implies that other factors included in words' meaning may have been responsible for the results obtained. Despite the fact that stimuli in the current experiment were carefully matched to all have neutral or moderate levels of factors such as arousal, concreteness, frequency of appearance and length, there is the possibility that they differ in other (possibly still undiscovered) ways. Therefore, it is advisable in future work to check the congruency of current results with 
another experimental manipulation that can be more definitively shown to directly trigger experiential vs. rational processing mechanisms.

The properties of the words used as experimental manipulation appeared to be crucial for task performance. In this experiment, two factors of valence and origin were orthogonally crossed in a $3 \times 3$ factorial manipulation in order to allow careful consideration of each factor's possible effects. It appears that indeed origin related complexity influenced the way decisions concerning an ambiguous task are made. Automatically originated words stimulated faster decisions, probably done with more ease using cognitive shortcuts (Kahneman 2011). The results for reflectively originated words contradict Kahneman's (2011) expectation that all emotional stimuli should provoke only fast processing. Some types of affective processes, based on multidimensional criteria of evaluation and deliberative appraisals, lead to slower decision making, and thus are probably underlined by more complex processing. The pattern of results obtained in this study suggests that the emotional complexity of affectively charged stimuli may lead to faster or slower responses, which supports the model presented in Fig. 2 (see also: Imbir 2016a). Finally, the results of the current study suggest that, indeed, affective and cognitive aspects of our mind may be understood from a dual-mind perspective, and some emotional stimuli derive from the rational mind. Those need the special attention of the scientific community.

Acknowledgments The project was funded by the National Science Center on the basis of decision DEC-2012/07/D/HS6/02013. The manuscript preparation was supported by the Faculty of Psychology via DSM grant (116702) awarded to Kamil Imbir.

Author Contributions K. K. Imbir is the sole author of this article and is responsible for its content.FundingThis study was funded by Narodowe Centrum Nauki (DEC-2012/07/D/HS6/02013) and Polish sources for science via DSM grant (116702) at Faculty of Psychology.

\section{Compliance with Ethical Standards}

Ethical Approval All procedures performed in studies involving human participants were in accordance with the ethical standards of the institutional and/or national research committee and with the 1964 Helsinki declaration and its later amendments or comparable ethical standards.

Informed Consent Oral informed consent was obtained from all individual participants included in the study.

Conflict of Interest The author declared no conflicts of interest with respect to the authorship or the publication of this article.

Open Access This article is distributed under the terms of the Creative Commons Attribution 4.0 International License (http:// creativecommons.org/licenses/by/4.0/), which permits unrestricted use, distribution, and reproduction in any medium, provided you give appropriate credit to the original author(s) and the source, provide a link to the Creative Commons license, and indicate if changes were made.

\section{References}

Antosz, A., \& Imbir, K. (2017). Effects of the emotional properties of words and a manipulation of mindset on performance of an ambiguous task. Journal of Cognitive Psychology, 29(2), 151-168. https:// doi.org/10.1080/20445911.2016.1226313.

Barber, H. A., Otten, L. J., Kousta, S. T., \& Vigliocco, G. (2013). Concreteness in word processing: ERP and behavioral effects in a lexical decision task. Brain and Language, 125(1), 47-53. https:// doi.org/10.1016/j.bandl.2013.01.005.

Błaszczak, W., \& Imbir, K. (2012). Use of affective priming to measure the implicit self-reference effect. Psychological Reports, 111(1), 107-114. https://doi.org/10.2466/07.21.24.PR0.111.4.107-114.

Burt, J. S. (2002). Why do non-color words interfere with color naming? Journal of Experimental Psychology: Human Perception and Performance, 28(5), 1019-1038. https://doi.org/10.1037/00961523.28.5.1019.

Clore, G. L., \& Huntsinger, J. R. (2007). How emotions inform judgment and regulate thought. Trends in Cognitive Science, 11, 393-399. https://doi.org/10.1016/j.tics.2007.08.005.

Damasio, A. (2010). Self comes to mind: Constructing the conscious mind. New York: Pantheon.

Eagleman, D. M. (2001). Visual illusions and neurobiology. Nature Reviews Neuroscience, 2(12), 920-926. https://doi.org/10.1038/ 35104092.

Ellsberg, D. (1961). Risk, ambiguity, and the Savage axioms. The Quarterly Journal of Economics, 75(4), 643-669 http://www.jstor. org/stable/1884324.

Epstein, S. (2003). Cognitive-experiential self-theory of personality. In T. Millon \& M. J. Lerner (Eds.), Handbook of psychology vol5: Personality and social psychology (pp. 159-184). Hoboken: Wiley.

Ferré, P., Guasch, M., Moldovan, C., \& Sánchez-Casas, R. (2012). Affective norms for 380 Spanish words belonging to three different semantic categories. Behavior Research Methods, 44(2), 395-403. https://doi.org/10.3758/s13428-011-0165-x.

Franz, V. H., Gegenfurtner, K. R., Bülthoff, H. H., \& Fahle, M. (2000). Grasping visual illusions: no evidence for a dissociation between perception and action. Psychological Science, 11(1), 20-25. https://doi.org/10.1111/1467-9280.00209.

Gawronski, B., \& Creighton, L. A. (2013). Dual-process theories. In D. E. Carlston (Ed.), The Oxford handbook of social cognition (pp. 282 312). New York: Oxford University Press.

Heath, C., \& Tversky, A. (1991). Preference and belief: ambiguity and competence in choice under uncertainty. Journal of Risk and Uncertainty, 4(1), 5-28. https://doi.org/10.1007/BF00057884.

Heathcote, A., Popiel, S. J., \& Mewhort, D. J. (1991). Analysis of response time distributions: an example using the Stroop task. Psychological Bulletin, 109(2), 340-347. https://doi.org/10.1037/ 0033-2909.109.2.340.

Imbir, K. (2015). Affective norms for 1,586 Polish words (ANPW): duality of mind approach. Behavior Research Methods, 47(3), 860870. https://doi.org/10.3758/s13428-014-0509-4.

Imbir, K. (2016a). From heart to mind and back again. A duality of emotion overview on emotion-cognition interactions. New Ideas in Psychology, 43, 39-49. https://doi.org/10.1016/j.newideapsych. 2016.04.001.

Imbir, K. (2016b). Affective norms for 4900 Polish words reload (ANPW_R): assessments for valence, arousal, dominance, origin, significance, concreteness, imageability and, age of acquisition. Frontiers in Psychology, 7, 1081. https://doi.org/10.3389/fpsyg. 2016.01081.

Imbir, K., \& Jarymowicz, M. (2013). The effect of automatic vs. reflective emotions on cognitive control in antisaccade tasks and the emotional stroop test. Polish Psychological Bulletin, 44(2), 137-146. https://doi.org/10.2478/ppb-2013-0016. 
Imbir, K., Spustek, T., \& Żygierewicz, J. (2016). Effects of valence and origin of emotions evidenced by ERP correlates in lexical decision task: the emotion duality approach. Frontiers in Psychology, 7, 271. https://doi.org/10.3389/fpsyg.2016.00271.

Jarymowicz, M., \& Imbir, K. (2015). Toward a human emotions taxonomy (based on their automatic vs. reflective origin). Emotion Review, 7(2), 183-188. https://doi.org/10.1177/1754073914555923.

Kagan, J. (2007). What is emotion? History, measures, and meanings. New Haven: Yale University Press.

Kahneman, D. (2011). Thinking. Fast and slow. New York: Farrar, Straus and Giroux.

Kanske, P., \& Kotz, S. A. (2007). Concreteness in emotional words: ERP evidence from a hemifield study. Brain Research, 1148, 138-148. https://doi.org/10.1016/j.brainres.2007.02.044.

Kazojć, J. (2011). Słownik frekwencyjny języka polskiego [Polish language dictionary of attendance]. Retrieved from: http://www. slowniki.org.pl/lista-frekwencyjna.pdf.

Keren, G., \& Schul, Y. (2009). Two is not always better than one a critical evaluation of two-system theories. Perspectives on Psychological Science, 4(6), 533-550. https://doi.org/10.1111/j.1745-6924.2009. 01164.x.

Lewis, M. (1995). Self-conscious emotions. American Scientist, 68-78.

Meier, B. P., Hauser, D. J., Robinson, M. D., Friesen, C. K., \& Schjeldahl, K. (2007). What's "up" with God? Vertical space as a representation of the divine. Journal of Personality and Social Psychology, 93(5), 699710. https://doi.org/10.1037/0022-3514. 93.5.699.

Moors, A., \& De Houwer, J. (2006). Automaticity: a theoretical and conceptual analysis. Psychological Bulletin, 132(2), 297-326. https://doi.org/10.1037/0033-2909.132.2.297.

Moors, A., De Houwer, J., Hermans, D., Wanmaker, S., van Schie, K., Van Harmelen, A. L., De Schryver, M., De Winne, J., \& Brysbaert, M. (2013). Norms of valence, arousal, dominance, and age of acquisition for 4,300 Dutch words. Behavior Research Methods, 45(1), 169177. https://doi.org/10.3758/s13428-012-0243-8.

Murphy, S. T., \& Zajonc, R. B. (1993). Affect, cognition, and awareness: affective priming with optimal and suboptimal stimulus exposures. Journal of Personality and Social Psychology, 64(5), 723-739. https://doi.org/10.1037/0022-3514.64.5.723.

Osgood, C. E., Suci, G., \& Tannenbaum, P. (1957). The measurement of meaning. Urbana: University of Illinois Press.
Palazova, M., Sommer, W., \& Schacht, A. (2013). Interplay of emotional valence and concreteness in word processing: An event-related potential study with verbs. Brain and Language, 125(3), 264-271. https://doi.org/10.1016/j.bandl.2013.02.008.

Payne, B. K., Cheng, C. M., Govorun, O., \& Stewart, B. D. (2005). An inkblot for attitudes: affect misattribution as implicit measurement. Journal of Personality and Social Psychology, 89(3), 277-293. https://doi.org/10.1037/0022-3514.89.3.277.

Reykowski, J. (1989). Dimensions of development of moral values. In N. Eisenberg, J. Reykowski, \& E. Staub (Eds.), Social and moral values (pp. 23-44). Hillsdale: Erlbaum.

Rolls, E. T. (2000). Precis of the brain and emotion. Behavioral and Brain Sciences, 23(2), 177-191. https://doi.org/10.1017/ S0140525X00002429.

Russell, J. A. (2003). Core affect and the psychological construction of emotion. Psychological Review, 110(1), 145-172. https://doi.org/10. 1037/0033-295X.110.1.145.

Scherer, K. R. (2004). Feelings integrate the central representation of appraisal-driven response organization in emotion. In A. S. R. Manstead, N. H. Frijda, \& A. H. Fischer (Eds.), Feelings and emotions. The Amsterdam symposium (pp. 136-157). Cambridge: Cambridge University Press.

Siegle, G. J., Ingram, R. E., \& Matt, G. E. (2002). Affective interference: an explanation for negative attention biases in dysphoria? Cognitive Therapy and Research, 26(1), 73-87. https://doi.org/10.1023/A: 1013893705009

Strack, F., \& Deutsch, R. (2004). Reflective and impulsive determinants of social behavior. Personality and Social Psychology Review, 8(3), 220-247. https://doi.org/10.1207/s15327957pspr0803 1.

Vigliocco, G., Kousta, S. T., Della Rosa, P. A., Vinson, D. P., Tettamanti, M., Devlin, J. T., \& Cappa, S. F. (2014). The neural representation of abstract words: the role of emotion. Cerebral Cortex, 24(7), 17671777. https://doi.org/10.1093/cercor/bht025.

Weiner, B. (2005). Social motivation, justice, and the moral emotions: An attributional approach. Mahwah, NJ: Lawrence Earlbaum.

Williams, J. M. G., Mathews, A., \& MacLeod, C. (1996). The emotional Stroop task and psychopathology. Psychological Bulletin, 120(1), 3-24. https://doi.org/10.1037/0033-2909.120.1.3.

Zajonc, R. B. (1980). Feeling and thinking: Preferences need no inferences. American Psychologist, 35, 151-175. https://doi.org/10. 1037/0003-066X.35.2.151 